\title{
Inosine - a Multifunctional Treatment for Complications of Neurologic Injury
}

\author{
Claire Doyle Vivian Cristofaro $^{\mathrm{b}, \mathrm{c}, \mathrm{d}} \quad$ Maryrose P. Sullivan ${ }^{\mathrm{b}, \mathrm{c}, \mathrm{d}} \quad$ Rosalyn M. Adam $^{\mathrm{a}, \mathrm{b}}$ \\ aUrological Diseases Research Center, Boston Children's Hospital, Boston, bDepartment of Surgery, \\ Harvard Medical School, Boston, 'Division of Urology, VA Boston Healthcare System, Boston, \\ 'Department of Surgery, Brigham and Women's Hospital, Boston, USA
}

\section{Key Words}

Purine $\cdot$ Nucleoside $\bullet$ Neuroprotective $\cdot$ Neurotrophic $\cdot$ Spinal cord injury $•$ Bladder

\begin{abstract}
Spinal cord injury (SCI) caused by trauma or disease leads to motor and sensory abnormalities that depend on the level, severity and duration of the lesion. The most obvious consequence of SCI is paralysis affecting lower and upper limbs. SCI also leads to loss of bladder and bowel control, both of which have a deleterious, life-long impact on the social, psychological, functional, medical and economic well being of affected individuals. Currently, there is neither a cure for SCI nor is there adequate management of its consequences. Although medications provide symptomatic relief for the complications of SCI including muscle spasms, lower urinary tract dysfunction and hyperreflexic bowel, strategies for repair of spinal injuries and recovery of normal limb and organ function are still to be realized. In this review, we discuss experimental evidence supporting the use of the naturally occurring purine nucleoside inosine to improve the devastating sequelae of SCI. Evidence suggests inosine is a safe, novel agent with multifunctional properties that is effective in treating complications of SCI and other neuropathies.

\section{Introduction}

Spinal cord injury (SCI) and other neurologic insults have devastating and often life-long consequences for its sufferers. Of the $\sim 200,000$ individuals living with SCI in the US, over $50 \%$ incurred their injury between the 16 and 30 years of age. As a result of advancements in initial stabilization and emergency medical management, survival of SCI victims increased in the second half of the $20^{\text {th }}$ century. In spite of this improvement, however, the lifespan of SCI sufferers is still reduced compared to the general population primarily as a result of systemic complications. In addition to paralysis, loss of both bladder and bowel control are among the most significant challenges faced by SCI sufferers $[1,2]$, contributing not only to social issues such as the stigma associated with urinary and fecal incontinence but also to elevated risk 
of urinary tract infections, renal damage, fecal impaction and megacolon. Bladder or bowel over-distension from urinary retention or fecal compaction in those with spinal cord injuries at T6 and above can also trigger autonomic dysreflexia, a dangerous hypertensive episode that can lead to life-threatening emergencies such as seizures, pulmonary edema, myocardial infarction and hemorrhagic stroke. Much of the cost related to medical management of SCI patients is directly associated with treatment of ongoing, lifelong symptoms, and runs into millions of dollars over the patient's lifetime. Thus, alternative treatments are urgently needed that are effective, have minimal side effects and yet are of reasonable cost for those with SCI to reduce the financial burden of their healthcare and improve quality of life. In this article, we will review the beneficial effects of the purine nucleoside inosine in the context of SCI and assess the evidence in support of its use in clinical management of the complications arising from SCI.

\section{Treatment strategies for SCI}

Currently there is no cure for the primary damage arising from SCI. Much effort has been expended to minimize secondary damage following injury with a variety of pharmacological approaches applied with variable success (reviewed in [3]). The corticosteroid methylprednisolone reduced inflammation and secondary damage following SCI, but only if administered within $8 \mathrm{~h}$ of injury, yielding no improvements in outcome with delayed administration [4, 5]. Moreover, significant side effects have been reported in patients receiving high dose methylprednisolone including infections, pneumonia, hyperglycemia and an elevated risk of skeletal muscle myopathy [6-8]. Current guidelines recommend that methylprednisolone is offered to patients within $8 \mathrm{~h}$ of acute SCI but that its use is at the discretion of the treating physician [5]. In preclinical studies, a variety of agents have shown beneficial effects in the context of traumatic SCI, many of which are anti-inflammatory and/or neuroprotective (reviewed in [9]). More recent strategies for treatment have taken advantage of advances in tissue engineering and stem cell technologies, as well as increased understanding of SCI pathobiology to encourage axonal regeneration through the native environment of the spinal cord. These include the use of cell-seeded or acellular scaffolds [10], administration of pharmacologic or antibody-based inhibitors of regeneration-inhibiting pathways to encourage regeneration and/or sprouting of axon collaterals [11,12], electrical rewiring strategies that take advantage of the innate ability of circuits within the spinal cord to execute sensory and motor tasks, and enhance this ability with an electrochemical strategy comprising lumbosacral electrical stimulation and systemic administration of serotonin and dopamine receptor agonists [13-15] and generation of new neurons with stem cell-based approaches (reviewed in [16]). Functional recovery has been demonstrated in human patients with SCI implanted with olfactory ensheathing cells in the injury site in the presence of a nerve graft for support $[17,18]$. In addition to recovery of ambulatory capability, there was evidence of some recovery of visceral (i.e. bladder and bowel) function, based on urodynamic and anal sphincter electromyographic analyses. However, in spite of encouraging results, the reproducibility of the approach remains to be demonstrated and this strategy appears to be some years away from routine clinical application.

\section{Inosine}

The purine nucleoside inosine is generated intracellularly and extracellularly by deamination of adenosine or intracellularly through the action of 5'-nucleotidase on inosine monophosphate. Inosine is further metabolized to hypoxanthine, xanthine and ultimately uric acid. Like adenosine, transport of inosine across the cell membrane is facilitated by equilibrative and concentrative nucleoside transporters. While the role of adenosine as a versatile signaling molecule is well documented, the biological actions of inosine continue to 
be uncovered. Under physiologic conditions, blood levels of inosine are increased by exercise and ingestion of certain foods (organ meats, beer, spinach) and exhibit diurnal variations. Over the past two decades, inosine has been shown to evoke significant improvements in motor function and visceral organ control in preclinical models of neurologic injury including SCI [19-24], stroke [25-29], traumatic brain injury [30], multiple sclerosis (MS) [31-35] and Parkinson's disease (PD) [36] through its ability to enhance the growth of axon collaterals from undamaged neurons. The basis of these beneficial effects stems from its antioxidant, anti-inflammatory, axogenic and neuroprotective properties (reviewed in [37]).

The neuroprotective potential of inosine was first suggested in a study showing that the active agent in liver cell conditioned medium, subsequently identified as inosine, was neurotrophic for cultured sympathetic neurons [38]. A series of subsequent studies identified growth-promoting activity of inosine in various neuronal cell types, comparable to that induced by canonical neurotrophic factors such as brain-derived neurotrophic factor (BDNF) or nerve growth factor (NGF) $[39,40]$. Benowitz and colleagues showed that inosine could promote axon outgrowth in a rat model of corticospinal tract injury [19]. In that study, inosine delivered into the sensorimotor cortex, promoted sprouting of collateral axons from uninjured neurons into the denervated region of the corticospinal tract. A follow-up study confirmed the ability of inosine to support compensatory growth of axons in this model and demonstrated significant improvements in motor function in inosine-treated rats as measured by performance in open-field testing and ladder rung walking tests [41].

Among the complications of SCI, the loss of bladder and bowel control have a profound negative impact on quality of life, contributing to anxiety, depression, decreased self-esteem, loss of independence and privacy, and requiring time-consuming management that restricts daily living. Neurogenic dysfunction of the bladder and bowel leads to psychosocial and medical complications, often exacerbated by limited mobility and dexterity, that include urinary and fecal incontinence, debilitating deficits in gut motility, recurrent urinary tract infections, hydronephrosis and irreversible kidney damage. Restoration of bladder and bowel function are consistently reported by those with SCI as top priorities for recovery [1, 2]. Therefore, better methods to alleviate these conditions and prevent their potentially lifethreatening consequences are needed. The ability of inosine to promote axon sprouting and synapse formation noted above provides a rationale for using this purine to improve bladder and bowel function following SCI. Although the effect of inosine on neurogenic bowel has not yet been tested, inosine has recently been shown to improve lower urinary tract function following SCI in rodents [22-24]. In patients with SCI above the lumbosacral region, the bladder loses inhibitory and voluntary input from higher centers and adopts a more primitive voiding behavior. This is characterized by detrusor overactivity (involuntary non-voiding bladder contractions during filling), and by detrusor-sphincter dyssynergia (abnormal contraction of the external urethral sphincter during detrusor contraction). These deficits arise from a multitude of pathological changes that occur after SCI, including alterations in sensory neurotransmission, remodeling of neuronal circuits within the spinal cord and interruption of spinobulbospinal pathways that normally control the micturition reflex and detrusor-external urethral sphincter coordination (reviewed in [42]). Our laboratory recently demonstrated improvements in detrusor overactivity in rats with complete thoracic (T8) spinal cord transection receiving systemic inosine daily for six weeks. Intraperitoneal administration of inosine immediately (i.e. within $3 \mathrm{~h}$ ) after injury resulted in significant reductions in frequency and amplitude of non-voiding contractions during filling cystometry [22]. Furthermore, we showed that inosine reduced detrusor overactivity in injured rats even when treatment was delayed for two months following injury. Thus, inosine was effective when administered in both preventive and intervention regimens. A subsequent study from our group revealed that inosine also reduced the frequency and amplitude of detrusor nonvoiding contractions in rats with SCI when delivered intravesically [24]. Consistent with our findings, Kuricova and colleagues found inosine could promote functional recovery, including reflex voiding activity in rats with SCI following oral administration [23]. 


\section{Cellular Physiology Cell Physiol Biochem 2018;49:2293-2303

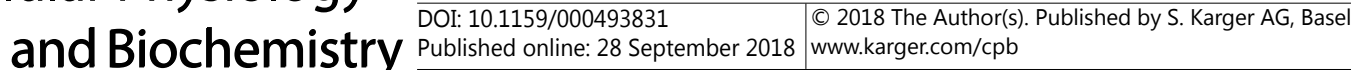 \\ Doyle et al.: Inosine and Spinal Cord Injury}

Although we did not define the precise mechanism of action in that study, the improvements in detrusor overactivity observed with chronic inosine administration were associated with changes in bladder innervation. Inosine partially prevented the loss of bladder staining for the pan-neuronal marker synaptophysin and the A $\delta$ fiber marker NF200 resulting from SCI, and attenuated the increase in staining for the C-fiber marker TRPV1 in vehicle-treated, spinalized animals. C-fiber afferent neurons have previously been implicated as key mediators of pathologic changes in voiding behavior following SCI or inflammatory insults, with TRPV1 desensitization using capsaicin or resiniferatoxin found to attenuate non-voiding contractions during cystometry [42-44]. These observations together with our findings, suggest that inosine improves detrusor overactivity, at least in part, via downregulation of TRPV1 levels and/or function. It is also possible that alterations in A $\delta$ fibers, as reflected by NF200 staining, contributed to the changes in non-voiding contractions observed in our study. As noted earlier, inosine has axogenic and neurotrophic activity [45, 46], consistent with an ability to promote regeneration of $A \delta$ fibers. However the extent to which this applies to $A \delta$ fibers in the bladder remains be to determined. The encouraging effects of inosine on preserving bladder innervation in our study are consistent with the neuroprotective properties ascribed to this purine and with previous data showing that inosine treatment partially prevented the reduction of bladder nerve density in an animal model of bladder outlet obstruction [47].

\section{Mechanisms of action}

Mechanistic studies in a variety of cell types have identified both receptor-dependent and receptor-independent activities of inosine in a variety of experimental models and disease settings. Benowitz and colleagues demonstrated that the neurotrophic activity of purines such as guanosine and adenosine in retinal ganglion cells was mediated through an intracellular mechanism [39]. In addition, adenosine required deamination to inosine to be active, since inhibition of adenosine deaminase prevented adenosine-stimulated axon outgrowth. Pharmacological blockade of the equilibrative nucleotide transporter (ENT) family of proteins inhibited the ability of inosine to stimulate axon outgrowth implicating facilitated diffusion through such transporters in intracellular entry of inosine. Furthermore, axon outgrowth stimulated by inosine was inhibited in part by the purine analog 6-thioguanine (6-TG) and by inhibitors of the kinases PI3K and MEK1/2, suggesting that inosine acts in part via modulation of kinase activity. Although the identity of the intracellular target of inosine was not determined in the study by Benowitz and colleagues [39], the authors speculated that it was related to an uncharacterized kinase activity previously described in the PC-12 neuronal cell line stimulated with NGF, i.e. protein kinase N [48]. Based on the antagonistic relationship between inosine and 6-TG in the context of axon outgrowth, where 6-TG inhibited inosine activity, together with the ability of 6-TG to inhibit the NGF-dependent kinase [45, 48, 49], Benowitz and colleagues suggested that inosine and 6-TG may compete for binding to the same target, such as protein kinase N. A subsequent study by Irwin and colleagues reported the purification of a kinase from bovine brain that showed homology to Mst3, and that was inhibited by 6-TG [40]. Mst3, comprising two splice variants Mst3a and Mst3b, is a member of the Ste20-like family of serine/threonine kinases initially identified in yeast (reviewed in [50]). Further analysis demonstrated that decreasing expression or activity of the Mst3b splice variant, but not the homolog Mst3a, attenuated NGF-stimulated neurite outgrowth in the PC-12 cell line and in primary cortical neurons. Moreover, these studies showed that inosine could stimulate neurite outgrowth independently of NGF, in an Mst3b-dependent manner [40]. Mst3b activity was shown subsequently to be required for both optic and radial nerve regeneration in vivo [51], and was shown to be increased by SCI in rats and to promote the regeneration of spinal cord neurons following injury [52]. In the latter study, Mst3b was shown to promote phosphorylation of B-Raf, MEK1 and ERK1/2 in PC-12 cells. Interestingly, findings from our group show that inosine stimulates rapid B-Raf phosphorylation in PC-12 
cells at doses in the micromolar range (R.M.A, unpublished observations). Taken together, these observations provide evidence for an intracellular mechanism of action of inosine via the purine-sensitive kinase Mst3b and its effector kinases.

The antioxidant and anti-inflammatory activities of inosine in certain contexts are also independent of cell-surface receptors. Inosine treatment improved learning and memory of aged rats and prevented ischemia-reperfusion induced gut barrier dysfunction by reducing lipid peroxidation and tissue cytokine levels $[53,54]$. The antioxidant properties of inosine are thought to be mediated, at least in part, by the peroxynitrite-scavenging capability of its metabolite uric acid (reviewed in [55]). This mechanism is supported by previous studies showing that production of reactive oxygen species due to enteropathy [56] or ischemiareperfusion can be attenuated by uric acid administration. Clinically, serum levels of uric acid have been associated with disease state in multiple sclerosis and Parkinson's disease, with increased serum urate levels associated with a significant reduction in risk of PD [57]. Conversely, reduced uric acid levels in plasma have been linked to increased risk of PD [58, 59]. Notably the reduction in circulating uric acid in patients at risk of PD provided the basis for therapeutic strategies aimed at increasing serum urate $[60,61]$. To obviate the rapid degradation of urate in the intestinal tract, its precursor inosine has been administered orally in clinical trials with the goal of elevating urate in this patient population to prevent and potentially reverse clinical decline (reviewed in [62]).

Receptor-dependent activities of inosine are mediated through one or more members of the adenosine receptor family, which is composed of distinct $A_{1}, A_{2 A^{\prime}} A_{2 B}$ and $A_{3}$ G-protein coupled receptor subtypes. Among adenosine receptors $A_{1}$ and $A_{3}$ couple to inhibitory $G$ proteins $\left(G_{i} \alpha\right)$, whereas $A_{2 A}$ and $A_{2 B}$ couple to $G_{s} \alpha$ proteins leading to differential regulation of adenylate cyclase, generation of cAMP and activation of cAMP-dependent protein kinase A (reviewed in [63]). Adenosine receptors have been implicated in a variety of biological processes relevant to central and peripheral nervous system function that are perturbed following SCI, including neurotransmission, inflammation and motor function. Adenosine and inosine are highly similar in structure, differing only by an amine group, but display very different stability, with the half-life of adenosine on the order of 10 seconds, versus $\sim 15 \mathrm{~h}$ for inosine [64]. This significant difference in stability suggests that the nature of signals elicited by inosine versus adenosine may diverge considerably. As discussed below, inosine has been shown to bind directly to $A_{1}, A_{2 A}$ and $A_{3}$ receptor subtypes [65-68], with affinities that are typically lower than that of adenosine. Although direct binding of inosine to $A_{2 B}$ has not been demonstrated, there is convincing evidence to suggest that inosine interacts functionally with all 4 adenosine receptor subtypes, to elicit a variety of effects depending on species and biological context [24, 35, 68-72]. A summary of the diverse biological activities of inosine mediated by adenosine receptors is provided in Table 1 .

Inosine was found to promote neurite outgrowth in and enhance the viability of neurons cultured from the neocortex of embryonic rats [72]. Blockade of either $A_{1}$ or $A_{2 A} A R$ using the pharmacologic antagonists 8-cyclopentyl theophylline (CPT) or 8-(3-chlorostyryl) caffeine (CSC), respectively, significantly reduced inosine-induced neurite outgrowth and viability. In the same study, oral administration of inosine to mice enhanced proliferation in the hippocampus that could be prevented by pharmacologic inhibition of $\mathrm{A}_{1}$ AR. In vivo

Table 1. Summary of biological activities of inosine mediated via adenosine receptors

\begin{tabular}{lccc}
\hline AR subtype & Target tissue & Biological effect & Reference \\
\hline $\mathrm{A}_{1}, \mathrm{~A}_{2 \mathrm{~A}}$ & Hind paw (rat, mouse) & Anti-nociception & {$[65,69]$} \\
$\mathrm{A}_{1}, \mathrm{~A}_{2 \mathrm{~A}}$ & Embryonic neocortex (rat) & Neurite outgrowth & {$[72]$} \\
$\mathrm{A}_{1}, \mathrm{~A}_{2 \mathrm{~A}}$ & Central nervous system (mouse) & Anti-depression & {$[70]$} \\
$\mathrm{A}_{2 \mathrm{~A}}$ & Lumbar spinal cord (mice) & Anti-nociception, & {$[35]$} \\
$\mathrm{A}_{2 \mathrm{~A}}, \mathrm{~A}_{2 \mathrm{~B}}$ & Bladder (rat) & Anti-inflammatory & {$[24]$} \\
$\mathrm{A}_{2 \mathrm{~A}}, \mathrm{~A}_{3}$ & Lung (mice) & Decreased spontaneous activity & {$[71]$} \\
$\mathrm{A}_{3}$ & Mast cells & Anti-inflammatory & {$[68]$} \\
\hline
\end{tabular}


administration of inosine also prevented depression-like behavior in animals that had been subjected to stress. In a separate study, Kaster and colleagues showed that antagonists of $\mathrm{A}_{1}$ and $\mathrm{A}_{2 \mathrm{~A}}$ receptors blocked the ability of inosine to reduce depression-like behavior [70] implicating these receptor subtypes in mediating inosine activity. The $A_{1}$ AR subtype has also been implicated in modulation of nociception by inosine in experimental pain models in rodents. Using a combination of pharmacological inhibition, together with antisense and knockout approaches to reduce or delete $\mathrm{A}_{1} \mathrm{AR}$ gene expression in vivo, Nascimento and colleagues demonstrated anti-nociceptive activity of inosine that was reduced or eliminated following $A_{1}$ AR knockdown or knockout $[65,69]$.

The $A_{2 A}$ receptor has also been shown to mediate the reduction in pain-associated behavior following inosine treatment [69]. In mice with paw pain from a variety of insults, inosine reduced mechanical and thermal allodynia in a manner that could be prevented by the $A_{2 A}$ antagonist, ZM241385 [69]. Thus, inosine signaling via $A_{2 A}$ is protective against pain. In contrast, in mice with experimental autoimmune encephalomyelitis (EAE), a model of multiple sclerosis, inosine administration conferred a protective effect that was associated with a decrease in levels of the $A_{2 A}$ receptor mRNA and protein in the lumbar spinal cord of mice with EAE [35]. In this model, inosine attenuated hyperalgesia, inhibited demyelination, reduced activation of astrocytes and decreased inflammation, thereby improving clinical outcomes in EAE mice. Thus, signaling via $A_{2 A}$ contributes to pathology in the EAE model. These contrasting observations are consistent with the known pleiotropic activity of the $A_{2 A}$ receptor depending on tissue type and disease model [63].

As noted previously, SCI evokes profound alterations in the function of the lower urinary tract. Bladder spontaneous activity, an intrinsic feature of bladder smooth muscle tissue is significantly increased in SCI rats, and is the ex vivo correlate of detrusor overactivity. Signaling via $A_{1}, A_{2 A}$ and $A_{2 B}$ receptors has been implicated in central and local modulation of normal and pathological bladder activity [24, 73-77]. Our group recently identified a new role for the $A_{2 B}$ adenosine receptor subtype in mediating the ability of inosine to decrease bladder spontaneous activity in SCI rats [24]. In our study, inosine evoked a dose-dependent reduction of spontaneous activity that was independent of the mucosa and prevented by pharmacological antagonists of $A_{2 \mathrm{~A}}$ (ZM241385) and $A_{2 B}$ (PSB603) receptors. In contrast, blockade of $A_{1}$ or $A_{3}$ receptors failed to inhibit inosine action. Consistent with this, a potent $A_{2 B}$ agonist (BAY60-6583) mimicked the activity of inosine, leading to a dose-dependent decrease in spontaneous activity. Although blockade of $A_{2 A}$ attenuated inosine activity, the $A_{2 A}$ agonist PSB0777 failed to reduce spontaneous activity significantly. Biochemical analysis of tissues revealed higher levels of $A_{2 B}$ than $A_{2 A}$ in detrusor tissues suggesting a potential difference in sensitivity to their respective agonists. Using pharmacological antagonists of potassium channels, we proceeded to implicate the large-conductance potassium (BK) channels expressed in smooth muscle as potential mediators of inosine action in bladder tissue. BK channels mediate hyperpolarization of the cell membrane and promote bladder smooth muscle relaxation [78]. We found that the BK channel blocker iberiotoxin prevented the inhibitory action of inosine on spontaneous activity in bladder tissues. In contrast, blockade of either SK3 small conductance potassium channels or $\mathrm{K}_{\text {ATP }}$ channels did not block the inhibitory activity of inosine on detrusor spontaneous activity. Together, these findings identify an important role for signaling via $\mathrm{A}_{2 \mathrm{~B}}$ receptors and $\mathrm{BK}$ channels in inosine-mediated regulation of spontaneous activity in the bladder. Importantly, they also demonstrate that the profound reduction in detrusor overactivity in rats with SCI treated with inosine occurs independently of cholinergic signaling, the primary target for medications used to manage detrusor overactivity in SCI patients. In our prior study, evoked contractions in bladder tissues generated either by electrical field stimulation or treatment with the cholinergic agonist carbachol were unaffected [22], suggesting that the intrinsic contractile capabilities of the bladder are not diminished by sustained inosine treatment. In fact, there was no evidence that long-term exposure to inosine in vivo was deleterious to lower urinary tract function. Of note, inosine has been used extensively as a nutritional supplement for many years, based on purported activity as a muscle stimulant $[79,80]$. No adverse effects have 
been reported, including in individuals consuming inosine for up to a year [81]. Thus, inosine may have clinical utility in patients who are refractory to or cannot tolerate anticholinergic pharmacotherapy, providing a safe alternative for management of overactivity.

\section{Inosine in clinical use}

Inosine has been used outside the US to preserve myocardial function during cardiogenic shock and cardiac surgery [82] and to prevent kidney damage during ischemic renal surgery [83]. The immunomodulatory effects of inosine contribute to the efficacy of Isoprinosine (inosine pranobex), a synthetic agent formed by inosine combined with the immunostimulant dimepranol acedoben (acetamidobenzoic acid and dimethylaminoisopropanol) that is used to treat acute respiratory viral infections, genital warts, herpes simplex infections, hepatitis $\mathrm{B}$ and subacute sclerosing panencephalitis.

Based on its efficacy in a variety of preclinical models, inosine has undergone evaluation in clinical trials in the US for multiple sclerosis (https://clinicaltrials.gov/ct2/show/ NCT00067327) [31, 32], amyotrophic lateral sclerosis (NCT02288091) and Parkinson's disease (http://clinicaltrials.gov/ct2/show/NCT00833690) [61, 84]. In each of these trials, the goal is to elevate levels of uric acid in serum and/or cerebrospinal fluid [85]. As noted earlier, inosine is metabolized to uric acid. From a mechanistic standpoint, uric acid is a peroxynitrite scavenger that is thought to mitigate the oxidative damage that contributes to the pathogenesis of MS [86] or PD [87]. In human subjects, serum levels of uric acid are inversely correlated with risk of PD [57-59], providing the rationale for clinical trials aimed at increasing urate levels. The Phase II study in Parkinson's disease revealed that oral inosine was safe and tolerated well by patients, even at doses of up to 3 grams per day [61]. Given the goal of increasing uric acid levels in the aforementioned clinical trials, concerns have been acknowledged regarding the potential for elevated risk of uric acid stones. However, the potential for stone formation in patients receiving inosine in the SURE-PD Phase II clinical trial was largely circumvented using a urine alkalinization protocol. In addition, a trial conducted in Japan reported no long-term adverse effects in a cohort of patients treated with $\sim 1$ gram inosine per day for 1 year, consistent with the safety of inosine in human studies [84]. A Phase III trial is currently recruiting patients to evaluate the efficacy of oral inosine in slowing clinical decline in early Parkinson's disease (http://clinicaltrials.gov/ct2/ show/NCT02642393). The ongoing clinical evaluation of inosine suggests its likely utility for a range of conditions arising from neurologic insults.

\section{Conclusion}

In summary, increasing pre-clinical and clinical evidence indicates that inosine is a safe, tolerable and effective therapeutic supplement for mitigating the cellular consequences of nerve injury, oxidative stress, inflammation, hypoxia and ischemia-reperfusion insults. As appreciated from the discussion above, inosine acts through a variety of different mechanisms, in a broad range of tissues, with minimal apparent adverse activity, and following diverse routes of administration. Its ready availability as an over-the-counter supplement provides a straightforward, relatively simply strategy for symptomatic relief and potential treatment of the debilitating consequences of a variety of neurologic and other impairments.

\section{Disclosure Statement}

The authors declare to have no competing interests. 


\section{Cellular Physiology Cell Physiol Biochem 2018;49:2293-2303

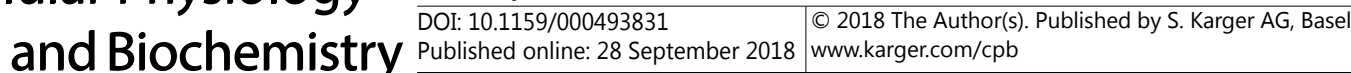

Doyle et al.: Inosine and Spinal Cord Injury

\section{References}

1 Anderson KD: Targeting recovery: priorities of the spinal cord-injured population. J Neurotrauma 2004;21:1371-1383.

2 Wyndaele JJ: The management of neurogenic lower urinary tract dysfunction after spinal cord injury. Nat Rev Urol 2016;13:705-714.

3 Hilton BJ, Moulson AJ, Tetzlaff W: Neuroprotection and secondary damage following spinal cord injury: concepts and methods. Neurosci Lett 2017;652:3-10.

4 Bracken MB: Steroids for acute spinal cord injury. Cochrane Database Syst Rev 2002;CD001046.

-5 Fehlings MG, Wilson JR, Harrop JS, Kwon BK, Tetreault LA, Arnold PM, Singh JM, Hawryluk G, Dettori JR: Efficacy and Safety of Methylprednisolone Sodium Succinate in Acute Spinal Cord Injury: A Systematic Review. Global Spine J 2017;7:116S-137S.

-6 Gerndt SJ, Rodriguez JL, Pawlik JW, Taheri PA, Wahl WL, Micheals AJ, Papadopoulos SM: Consequences of high-dose steroid therapy for acute spinal cord injury. J Trauma 1997;42:279-284.

7 Suberviola B, Gonzalez-Castro A, Llorca J, Ortiz-Melon F, Minambres E: Early complications of high-dose methylprednisolone in acute spinal cord injury patients. Injury 2008;39:748-752.

-8 Qian T, Guo X, Levi AD, Vanni S, Shebert RT, Sipski ML: High-dose methylprednisolone may cause myopathy in acute spinal cord injury patients. Spinal Cord 2005;43:199-203.

-9 Kabu S, Gao Y, Kwon BK, Labhasetwar V: Drug delivery, cell-based therapies, and tissue engineering approaches for spinal cord injury. J Control Release 2015;219:141-154.

10 Liu S, Schackel T, Weidner N, Puttagunta R: Biomaterial-Supported Cell Transplantation Treatments for Spinal Cord Injury: Challenges and Perspectives. Front Cell Neurosci 2017;11:430.

11 Festoff BW: Designing drugs that encourage spinal cord injury healing. Expert Opin Drug Discov 2014;9:1151-1165.

12 Cox A, Varma A, Banik N: Recent advances in the pharmacologic treatment of spinal cord injury. Metab Brain Dis 2015;30:473-482.

-13 van den Brand R, Heutschi J, Barraud Q, DiGiovanna J, Bartholdi K, Huerlimann M, Friedli L, Vollenweider I, Moraud EM, Duis S, Dominici N, Micera S, Musienko P, Courtine G: Restoring voluntary control of locomotion after paralyzing spinal cord injury. Science 2012;336:1182-1185.

14 van den Brand R, Mignardot JB, von Zitzewitz J, Le Goff C, Fumeaux N, Wagner F, Capogrosso M, Martin Moraud E, Micera S, Schurch B, Curt A, Carda S, Bloch J, Courtine G: Neuroprosthetic technologies to augment the impact of neurorehabilitation after spinal cord injury. Ann Phys Rehabil Med 2015;58:232237.

15 Knudsen EB, Moxon KA: Restoration of Hindlimb Movements after Complete Spinal Cord Injury Using Brain-Controlled Functional Electrical Stimulation. Front Neurosci 2017;11:715.

16 Dalamagkas K, Tsintou M, Seifalian AM: Stem cells for spinal cord injuries bearing translational potential. Neural Regen Res 2018;13:35-42.

17 Tabakow P, Jarmundowicz W, Czapiga B, Fortuna W, Miedzybrodzki R, Czyz M, Huber J, Szarek D, Okurowski S, Szewczyk P, Gorski A, Raisman G: Transplantation of autologous olfactory ensheathing cells in complete human spinal cord injury. Cell Transplant 2013;22:1591-1612.

18 Tabakow P, Raisman G, Fortuna W, Czyz M, Huber J, Li D, Szewczyk P, Okurowski S, Miedzybrodzki R, Czapiga B, Salomon B, Halon A, Li Y, Lipiec J, Kulczyk A, Jarmundowicz W: Functional regeneration of supraspinal connections in a patient with transected spinal cord following transplantation of bulbar olfactory ensheathing cells with peripheral nerve bridging. Cell Transplant 2014;23:1631-1655.

19 Benowitz LI, Goldberg DE, Madsen JR, Soni D, Irwin N: Inosine stimulates extensive axon collateral growth in the rat corticospinal tract after injury. Proc Natl Acad Sci U S A 1999;96:13486-13490.

20 Liu F, You SW, Yao LP, Liu HL, Jiao XY, Shi M, Zhao QB, Ju G: Secondary degeneration reduced by inosine after spinal cord injury in rats. Spinal Cord 2006;44:421-426.

21 Conta AC, Stelzner DJ: Immunomodulatory effect of the purine nucleoside inosine following spinal cord contusion injury in rat. Spinal Cord 2008;46:39-44.

-22 Chung YG, Seth A, Doyle C, Franck D, Kim D, Cristofaro V, Benowitz LI, Tu DD, Estrada CR, Mauney JR, Sullivan MP, Adam RM: Inosine Improves Neurogenic Detrusor Overactivity following Spinal Cord Injury. PLoS One 2015;10:e0141492. 


\section{Cellular Physiology Cell Physiol Biochem 2018;49:2293-2303 \begin{tabular}{l|l|l} 
and Biochemistry Published online: 28 September 2018 & $\begin{array}{l}\text { (c) } 2018 \text { The Author(s). Published by S. Karger AG, Basel } \\
\text { www.karger.com/cpb }\end{array}$ \\
\hline
\end{tabular} \\ Doyle et al.: Inosine and Spinal Cord Injury}

23 Kuricova M, Ledecky V, Liptak T, Madari A, Grulova I, Slovinska L, Nagyova M, Cizkova D: Oral administration of inosine promotes recovery after experimental spinal cord injury in rat. Neurol Sci 2014;35:1785-1791.

24 Doyle C, Cristofaro V, Sack BS, Lukianov SN, Schafer M, Chung YG, Sullivan MP, Adam RM: Inosine attenuates spontaneous activity in the rat neurogenic bladder through an A2B pathway. Sci Rep 2017;7:44416.

25 Chen P, Goldberg DE, Kolb B, Lanser M, Benowitz LI: Inosine induces axonal rewiring and improves behavioral outcome after stroke. Proc Natl Acad Sci U S A 2002;99:9031-9036.

-26 Shen H, Chen GJ, Harvey BK, Bickford PC, Wang Y: Inosine reduces ischemic brain injury in rats. Stroke 2005;36:654-659.

-27 Zai L, Ferrari C, Subbaiah S, Havton LA, Coppola G, Strittmatter S, Irwin N, Geschwind D, Benowitz LI: Inosine alters gene expression and axonal projections in neurons contralateral to a cortical infarct and improves skilled use of the impaired limb. J Neurosci 2009;29:8187-8197.

-28 Zai L, Ferrari C, Dice C, Subbaiah S, Havton LA, Coppola G, Geschwind D, Irwin N, Huebner E, Strittmatter SM, Benowitz LI: Inosine augments the effects of a Nogo receptor blocker and of environmental enrichment to restore skilled forelimb use after stroke. J Neurosci 2011;31:5977-5988.

-29 Moore TL, Pessina MA, Finklestein SP, Killiany RJ, Bowley B, Benowitz L, Rosene DL: Inosine enhances recovery of grasp following cortical injury to the primary motor cortex of the rhesus monkey. Restor Neurol Neurosci 2016;34:827-848.

-30 Dachir S, Shabashov D, Trembovler V, Alexandrovich AG, Benowitz LI, Shohami E: Inosine improves functional recovery after experimental traumatic brain injury. Brain Res 2014;1555:78-88.

-31 Spitsin S, Hooper DC, Leist T, Streletz LJ, Mikheeva T, Koprowskil H: Inactivation of peroxynitrite in multiple sclerosis patients after oral administration of inosine may suggest possible approaches to therapy of the disease. Mult Scler 2001;7:313-319.

-32 Spitsin S, Markowitz CE, Zimmerman V, Koprowski H, Hooper DC: Modulation of serum uric acid levels by inosine in patients with multiple sclerosis does not affect blood pressure. J Hum Hypertens 2010;24:359362.

33 Scott GS, Spitsin SV, Kean RB, Mikheeva T, Koprowski H, Hooper DC: Therapeutic intervention in experimental allergic encephalomyelitis by administration of uric acid precursors. Proc Natl Acad Sci U S A 2002;99:16303-16308.

34 Markowitz CE, Spitsin S, Zimmerman V, Jacobs D, Udupa JK, Hooper DC, Koprowski H: The treatment of multiple sclerosis with inosine. J Altern Complement Med 2009;15:619-625.

35 Junqueira SC, Dos Santos Coelho I, Lieberknecht V, Cunha MP, Calixto JB, Rodrigues ALS, Santos ARS, Dutra RC: Inosine, an Endogenous Purine Nucleoside, Suppresses Immune Responses and Protects Mice from Experimental Autoimmune Encephalomyelitis: a Role for A2A Adenosine Receptor. Mol Neurobiol 2017;54:3271-3285.

-36 Schwarzschild MA, Macklin EA, Ascherio A: Urate and neuroprotection trials. Lancet Neurol 2014;13:758.

-37 Hasko G, Sitkovsky MV, Szabo C: Immunomodulatory and neuroprotective effects of inosine. Trends Pharmacol Sci 2004;25:152-157.

-38 Zurn AD, Do KQ: Purine metabolite inosine is an adrenergic neurotrophic substance for cultured chicken sympathetic neurons. Proc Natl Acad Sci U S A 1988;85:8301-8305.

39 Benowitz LI, Jing Y, Tabibiazar R, Jo SA, Petrausch B, Stuermer CA, Rosenberg PA, Irwin N: Axon outgrowth is regulated by an intracellular purine-sensitive mechanism in retinal ganglion cells. J Biol Chem 1998;273:29626-29634.

40 Irwin N, Li YM, O’Toole JE, Benowitz LI: Mst3b, a purine-sensitive Ste20-like protein kinase, regulates axon outgrowth. Proc Natl Acad Sci U S A 2006;103:18320-18325.

41 Kim D, Zai L, Liang P, Schaffling C, Ahlborn D, Benowitz LI: Inosine enhances axon sprouting and motor recovery after spinal cord injury. PLoS One 2013;8:e81948.

42 de Groat WC, Yoshimura N: Mechanisms underlying the recovery of lower urinary tract function following spinal cord injury. Prog Brain Res 2006;152:59-84.

43 Komiyama I, Igawa Y, Ishizuka 0, Nishizawa 0, Andersson KE: Effects of intravesical capsaicin and resiniferatoxin on distension-induced bladder contraction in conscious rats with and without chronic spinal cord injury. J Urol 1999;161:314-319.

44 Juszczak K, Ziomber A, Wyczolkowski M, Thor PJ: Urodynamic effects of the bladder C-fiber afferent activity modulation in chronic model of overactive bladder in rats. J Physiol Pharmacol 2009;60:85-91. 


\section{Cellular Physiology Cell Physiol Biochem 2018;49:2293-2303

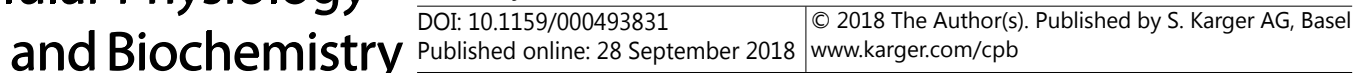

45 Petrausch B, Tabibiazar R, Roser T, Jing Y, Goldman D, Stuermer CA, Irwin N, Benowitz LI: A purinesensitive pathway regulates multiple genes involved in axon regeneration in goldfish retinal ganglion cells. J Neurosci 2000;20:8031-8041.

46 Wu MM, You SW, Hou B, Jiao XY, Li YY, Ju G: Effects of inosine on axonal regeneration of axotomized retinal ganglion cells in adult rats. Neurosci Lett 2003;341:84-86.

-47 Liu F, Yao L, Yuan J, Liu H, Yang X, Qin W, Wu G, Yang L, Wang H, Takahashi N, Yamaguchi O: Protective effects of inosine on urinary bladder function in rats with partial bladder outlet obstruction. Urology 2009;73:1417-1422.

-48 Volonte C, Greene LA: Nerve growth factor-activated protein kinase N. Characterization and rapid near homogeneity purification by nucleotide affinity-exchange chromatography. J Biol Chem 1992;267:2166321670.

49 Volonte C, Rukenstein A, Loeb DM, Greene LA: Differential inhibition of nerve growth factor responses by purine analogues: correlation with inhibition of a nerve growth factor-activated protein kinase. J Cell Biol 1989;109:2395-2403.

-50 Ling P, Lu TJ, Yuan CJ, Lai MD: Biosignaling of mammalian Ste20-related kinases. Cell Signal 2008;20:12371247.

51 Lorber B, Howe ML, Benowitz LI, Irwin N: Mst3b, an Ste20-like kinase, regulates axon regeneration in mature CNS and PNS pathways. Nat Neurosci 2009;12:1407-1414.

-52 Zhang Y, Hu H, Tian T, Zhang L, Zhao D, Wu Q, Chang Y, Wang Q, Zhou S, Feng G, Huang F: Mst3b promotes spinal cord neuronal regeneration by promoting growth cone branching out in spinal cord injury rats. Mol Neurobiol 2015;51:1144-1157.

53 Ruhal P, Dhingra D: Inosine improves cognitive function and decreases aging-induced oxidative stress and neuroinflammation in aged female rats. Inflammopharmacology 2018; DOI:10.1007/s10787-018-0476-y.

54 Dowdall JF, Winter DC, Bouchier-Hayes DJ: Inosine modulates gut barrier dysfunction and end organ damage in a model of ischemia-reperfusion injury. J Surg Res 2002;108:61-68. Becker BF: Towards the physiological function of uric acid. Free Radic Biol Med 1993;14:615-631. Yasutake Y, Tomita K, Higashiyama M, Furuhashi H, Shirakabe K, Takajo T, Maruta K, Sato H, Narimatsu K, Yoshikawa K, Okada Y, Kurihara C, Watanabe C, Komoto S, Nagao S, Matsuo H, Miura S, Hokari R: Uric acid ameliorates indomethacin-induced enteropathy in mice through its antioxidant activity. J Gastroenterol Hepatol 2017;32:1839-1845.

57 de Lau LM, Koudstaal PJ, Hofman A, Breteler MM: Serum uric acid levels and the risk of Parkinson disease. Ann Neurol 2005;58:797-800.

58 Andreadou E, Nikolaou C, Gournaras F, Rentzos M, Boufidou F, Tsoutsou A, Zournas C, Zissimopoulos V, Vassilopoulos D: Serum uric acid levels in patients with Parkinson's disease: their relationship to treatment and disease duration. Clin Neurol Neurosurg 2009;111:724-728.

59 Paganoni S, Schwarzschild MA: Urate as a Marker of Risk and Progression of Neurodegenerative Disease. Neurotherapeutics 2017;14:148-153.

60 Schwarzschild MA, Schwid SR, Marek K, Watts A, Lang AE, Oakes D, Shoulson I, Ascherio A, Parkinson Study Group PI, Hyson C, Gorbold E, Rudolph A, Kieburtz K, Fahn S, Gauger L, Goetz C, Seibyl J, Forrest M, Ondrasik J: Serum urate as a predictor of clinical and radiographic progression in Parkinson disease. Arch Neurol 2008;65:716-723.

61 Schwarzschild MA, Ascherio A, Beal MF, Cudkowicz ME, Curhan GC, Hare JM, Hooper DC, Kieburtz KD, Macklin EA, Oakes D, Rudolph A, Shoulson I, Tennis MK, Espay AJ, Gartner M, Hung A, Bwala G, Lenehan $\mathrm{R}$, Encarnacion E, Ainslie M, et al.: Inosine to increase serum and cerebrospinal fluid urate in Parkinson disease: a randomized clinical trial. JAMA Neurol 2014;71:141-150.

62 Crotty GF, Ascherio A, Schwarzschild MA: Targeting urate to reduce oxidative stress in Parkinson disease. Exp Neurol 2017;298:210-224.

63 Wei CJ, Li W, Chen JF: Normal and abnormal functions of adenosine receptors in the central nervous system revealed by genetic knockout studies. Biochim Biophys Acta 2011;1808:1358-1379.

64 Viegas TX, Omura GA, Stoltz RR, Kisicki J: Pharmacokinetics and pharmacodynamics of peldesine (BCX-34), a purine nucleoside phosphorylase inhibitor, following single and multiple oral doses in healthy volunteers. J Clin Pharmacol 2000;40:410-420. 


\section{Cellular Physiology Cell Physiol Biochem 2018;49:2293-2303 \begin{tabular}{l|l|l} 
and Biochemistry Published online: 28 September 2018 & $\begin{array}{l}\text { (c) } 2018 \text { The Author(s). Published by S. Karger AG, Basel } \\
\text { www.karger.com/cpb }\end{array}$
\end{tabular} \\ Doyle et al.: Inosine and Spinal Cord Injury}

65 Nascimento FP, Macedo-Junior SJ, Pamplona FA, Luiz-Cerutti M, Cordova MM, Constantino L, Tasca CI, Dutra RC, Calixto JB, Reid A, Sawynok J, Santos AR: Adenosine A1 receptor-dependent antinociception induced by inosine in mice: pharmacological, genetic and biochemical aspects. Mol Neurobiol 2015;51:1368-1378.

66 Welihinda AA, Kaur M, Greene K, Zhai Y, Amento EP: The adenosine metabolite inosine is a functional agonist of the adenosine A2A receptor with a unique signaling bias. Cell Signal 2016;28:552-560.

67 Welihinda AA, Kaur M, Raveendran KS, Amento EP: Enhancement of inosine-mediated A2AR signaling through positive allosteric modulation. Cell Signal 2018;42:227-235.

-68 Jin X, Shepherd RK, Duling BR, Linden J: Inosine binds to A3 adenosine receptors and stimulates mast cell degranulation. J Clin Invest 1997;100:2849-2857.

-69 Nascimento FP, Figueredo SM, Marcon R, Martins DF, Macedo SJ, Jr., Lima DA, Almeida RC, Ostroski RM, Rodrigues AL, Santos AR: Inosine reduces pain-related behavior in mice: involvement of adenosine A1 and A2A receptor subtypes and protein kinase C pathways. J Pharmacol Exp Ther 2010;334:590-598.

70 Kaster MP, Budni J, Gazal M, Cunha MP, Santos AR, Rodrigues AL: The antidepressant-like effect of inosine in the FST is associated with both adenosine A1 and A 2A receptors. Purinergic Signal 2013;9:481-486.

71 da Rocha Lapa F, de Oliveira AP, Accetturi BG, de Oliveira Martins I, Domingos HV, de Almeida Cabrini D, de Lima WT, Santos AR: Anti-inflammatory effects of inosine in allergic lung inflammation in mice: evidence for the participation of adenosine A2A and A 3 receptors. Purinergic Signal 2013;9:325-336.

72 Muto J, Lee H, Lee H, Uwaya A, Park J, Nakajima S, Nagata K, Ohno M, Ohsawa I, Mikami T: Oral administration of inosine produces antidepressant-like effects in mice. Sci Rep 2014;4:4199.

73 Sosnowski M, Yaksh TL: The role of spinal and brainstem adenosine receptors in the modulation of the volume-evoked micturition reflex in the unanesthetized rat. Brain Res 1990;515:207-213.

-74 Gopalakrishnan SM, Buckner SA, Milicic I, Groebe DR, Whiteaker KL, Burns DJ, Warrior U, Gopalakrishnan M: Functional characterization of adenosine receptors and coupling to ATP-sensitive K+ channels in Guinea pig urinary bladder smooth muscle. J Pharmacol Exp Ther 2002;300:910-917.

-75 Kitta T, Chancellor MB, de Groat WC, Kuno S, Nonomura K, Yoshimura N: Suppression of bladder overactivity by adenosine A2A receptor antagonist in a rat model of Parkinson disease. J Urol 2012;187:1890-1897.

76 Kitta T, Chancellor MB, de Groat WC, Kuno S, Nonomura K, Yoshimura N: Roles of adenosine A1 and A2A receptors in the control of micturition in rats. Neurourol Urodyn 2014;33:1259-1265.

77 Pakzad M, Ikeda Y, McCarthy C, Kitney DG, Jabr RI, Fry CH: Contractile effects and receptor analysis of adenosine-receptors in human detrusor muscle from stable and neuropathic bladders. Naunyn Schmiedebergs Arch Pharmacol 2016;389:921-929.

78 Hashitani H, Brading AF: Ionic basis for the regulation of spontaneous excitation in detrusor smooth muscle cells of the guinea-pig urinary bladder. Br J Pharmacol 2003;140:159-169.

79 Williams MH, Kreider RB, Hunter DW, Somma CT, Shall LM, Woodhouse ML, Rokitski L: Effect of inosine supplementation on 3-mile treadmill run performance and VO2 peak. Med Sci Sports Exerc 1990;22:517522.

80 McNaughton L, Dalton B, Tarr J: Inosine supplementation has no effect on aerobic or anaerobic cycling performance. Int J Sport Nutr 1999;9:333-344.

-81 Cheng Y, Jiang DH: [Therapeutic effect of inosine in Tourette syndrome and its possible mechanism of action]. Zhonghua Shen Jing Jing Shen Ke Za Zhi 1990;23:90-93, 126-127.

82 de Jong JW, Czarnecki W, Ruzyllo W, Huizer T, Herbaczynska-Cedro K: Apparent inosine uptake by the human heart. Cardiovasc Res 1989;23:484-488.

-83 Fitzpatrick JM, Wallace DM, Whitfield HN, Watkinson LE, Fernando AR, Wickham JE: Inosine in ischaemic renal surgery: long-term follow-up. Br J Urol 1981;53:524-527.

84 Iwaki H, Ando R, Miyaue N, Tada S, Tsujii T, Yabe H, Nishikawa N, Nagai M, Nomoto M: One year safety and efficacy of inosine to increase the serum urate level for patients with Parkinson's disease in Japan. J Neurol Sci 2017;383:75-78.

85 Chen X, Wu G, Schwarzschild MA: Urate in Parkinson's disease: more than a biomarker? Curr Neurol Neurosci Rep 2012;12:367-375.

86 Spitsin S, Koprowski H: Role of uric acid in multiple sclerosis. Curr Top Microbiol Immunol 2008;318:325342.

87 Cipriani S, Bakshi R, Schwarzschild MA: Protection by inosine in a cellular model of Parkinson's disease. Neuroscience 2014;274:242-249. 